\title{
Chronic pain/dysaesthesiae in spinal cord injury patients: results of a multicentre study
}

\author{
S Störmer ${ }^{1}$, HJ Gerner ${ }^{1}$, W Grüninger ${ }^{2}$, K Metzmacher ${ }^{1}$, S Föllinger ${ }^{2}$, Ch Wienke ${ }^{4}$, W Aldinger ${ }^{5}$, N Walker ${ }^{5}$, \\ M Zimmermann ${ }^{3}$ and V Paeslack ${ }^{1}$ \\ ${ }^{1}$ Stiftung Orthopädische Universitätsklinik, Heidelberg (Foundation Orthopedic University Clinic, Heidelberg); \\ ${ }^{2}$ Krankenhaus Hohe Warte, Bayreuth (Hospital Hohe Warte, Bayreuth); ${ }^{3}$ Physiologisches Institut II der Universität \\ Heidelberg (Institute for Physiology II of the University of Heidelberg); ${ }^{4}$ Werner-Wicker-Klinik, Bad Wildungen- \\ West (Werner-Wicker-Clinic, Bad Wildungen-West); ${ }^{5}$ Orthopädische Klinik, Markgröningen (Orthopedic Clinic, \\ Markgröningen), Germany
}

\begin{abstract}
The aim of the multicentre study* entitled 'Description and Documentation of Painful States in Spinal Cord Injury Patients', in addition to the description and documentation of chronic pain and stressful dysaesthesiae in SCI patients, was the search for correlations between these symptoms and medical and psychosocial variables. To this end, the sample was selected to be as representative as possible. All patients referred for in-patient or out-patient treatment at the centres taking part were enrolled in the study in order of presentation, providing they gave consent and met the inclusion criteria. Psychosocial, medical and demographic data were elicited by a standardized battery of questions and a standardized physical examination, as were any chronic pain/dysaesthesiae $(\mathrm{P} / \mathrm{D})$ present in any localization. Among 901 patients, $34 \%$ had no chronic pain or dysaesthesiae, $50 \%$ had pain only, $11 \%$ had painful dysaesthesiae and $5 \%$, non-painful but chronic and distressing dysaesthesiae. The intensity of $\mathrm{P} / \mathrm{D}$ was noted as seven or more on a $10 \mathrm{~cm}$ visual analogue scale by $61 \%$ of the patients affected and was experienced as rather or very distressing in $75 \%$ of cases. Most $(86 \%) \mathrm{P} / \mathrm{D}$ were located below the spinal lesion or in the transition zone. There were significant correlations between the presence of $\mathrm{P} / \mathrm{D}$ and age on questioning and at onset of the paraplegia/tetraplegia, problems with rectal paralysis, expectations of life as a paraplegic/tetraplegic, and subjective assessment of changes in working life. Highly significant correlations were found with subjective distress resulting of paraplegia/tetraplegia as such, depressed mood and psychosomatic disturbances of wellbeing. Overall, among the selected variables of our study, we found that correlations between $\mathrm{P} / \mathrm{D}$ and psychosocial variables were more frequent and closer than those between $\mathrm{P} / \mathrm{D}$ and medical variables.
\end{abstract}

Keywords: pain; dysaesthesia; paraplegia; tetraplegia; spinal cord injury; multicentre study

\section{Introduction}

It has always seemed paradoxical that SCI patients with complete paraplegia or tetraplegia report pain often strictly localized - in the part of the body with complete sensory loss, where even surgical operations can be performed without anaesthesia. Accordingly, pain in SCI patients has occupied scientists for a long time - but so far no exhaustive explanation or satisfactory therapy has been found.

Initially only pain located in the paralysed area of the body or at least in the transition zone between the paralysed and the non-paralysed areas of the body

Correspondence: S Störmer, Rollwiesenweg 20, D-3509, Marburg, Germany

*This study was supported by the German Federal Ministry for Education and Science, Research and Technology [BMBF] with grant no. $01 \mathrm{EM} 9414$ seemed to be of interest in scientific reports and descriptions. Later other pains also seemed worth mentioning. This is reflected in the classifications that were proposed in the past, which grouped different types of pain according to various criteria. One of the oldest classifications, which is nonetheless still current, is the division into three types of pain: 'burning infralesional pain', 'visceral pain', and 'radicular pain', as published by Pollock et al, ${ }^{1}$ Wright and Sweet ${ }^{2}$ and also Melzack and Loeser. ${ }^{3}$ Woolsey ${ }^{4}$ and Donovan et $a l^{5}$ adopted this classification, but extended it by 'psychogenic pain' and 'pain in the neck and shoulder region'. Maury ${ }^{6}$ distinguished all sorts of pain including those not specific to SCI patients, such as the precordial pain of ischaemia in coronary heart disease - solely according to the localization in relation to the level of the lesion (above and below 
the lesion, at the level of the lesion). Waisbrod et $a l^{7}$ selected three categories of pain, determined by the mode of precipitation: 'projected pain' (corresponding to burning infralesional pain), 'mechanical pain at the site of the lesion', and 'triggered pain'. However, although there is meanwhile quite a large body of literature on pain in SCI patients, the problems of its origin and of its treatment cannot be regarded as solved.

\section{Objective}

The aims of the project 'Description and Documentation of Painful Conditions in Spinal Cord Injury Patients' were the description and documentation of chronic pain and distressing dysaesthesiae as mentioned in the project title, and especially their prevalence. A further objective of the study was the search for correlations between these $\mathrm{P} / \mathrm{D}$ and medical and psychosocial variables. The investigation was conducted as a multicentre study in four German spinal cord injury centres, namely Bad Wildungen, Bayreuth, Heidelberg and Markgröningen, all data used being ascertained in the years 1993-1996.

\section{Materials and methods}

\section{Objects of our investigation}

For the purposes of the project chronic pains and distressing dysaesthesiae were taken to mean: pain alone, of any intensity, and also distressing dysaesthesiae whether or not these were painful. These symptoms were required to have persisted continuously for 3 months or with remissions and relapses for 6 months (definition of chronicity) and not to have started until after SCI. The painless, but distressing, dysaesthesiae were included because preliminary investigations had suggested that infralesional dysaesthesia and pain could be two different manifestations of the same underlying phenomenon. Dysaesthesiae that are experienced sometimes as painless and sometimes as painful are seen as the link between the two poles of 'pure pain' and 'pure dysaesthesia' (with no pain component).

To make the patient sample as representative as possible for SCI patients, it was decided that during the study period all consecutive patients presenting as in-patients or out-patients at the centres would be included insofar as they gave their informed consent and met the inclusion and exclusion criteria, regardless of whether they were experiencing $\mathrm{P} / \mathrm{D}$ or not. So the patients without pain or distressing dysaesthesia could function as a control group when relationships between pain and other variables were sought.

The most important inclusion and exclusion criteria were:

- Patient age of at least 18 years was required.

- Paraplegia or tetraplegia must have pre-existed for at least 2 years.
- Neurological system diseases (eg multiple sclerosis, Recklinghausen disease), malignant tumour disease, dysraphias and craniocerebral trauma with permanent damage (and all illnesses that can precipitate paralytic or painful conditions that overlap inextricably with paralysis and pain caused by SCI) led to exclusion.

- All conditions that would preclude reliability of an interview (eg acute deterioration of a psychosis) led to exclusion.

Data were ascertained for two patient groups:

Sample A:

In sample A (total patient population) all patients were ascertained; the basic data that are identical for all patients were elicited. These include:

- A standardized interview based on a questionnaire ((pain) questionnaire for SCI patients (SFB)); this includes questions on the paralysis as such, on its causation and on its sequelae from the physical, vocational, and financial aspects and also with reference to how it affects family life and other social interactions. If pain or dysaesthesiae had also developed after SCI, a detailed documentation of the pain experienced followed (with the aid of an adapted and modified version of H Seemann's pain questionnaire $){ }^{8}$ recording localization of the pain and its intensity, duration, development over time, and favourable and unfavourable influential factors, etc.

- A medical history was elicited from all patients and they were also required to undergo a standardized physical examination in the scope of the annual routine check-ups.

Sample B:

Sample B (a subsample of sample A) was examined even more intensively. In addition to the investigations detailed above for sample $\mathrm{A}$, the patients in this subsample also:

- underwent an in-depth, also standardized, interview on psychosocial questions, which was based on another questionnaire (psychosocial questionnaire (PSF)),

- kept a pain diary for three periods of 1 week each,

- were questioned more closely to elicit a more detailed medical and pain history and were subjected to a more detailed medical examination that also involved instrumental means of diagnosis (MRI, ultrasound, SEP, X-ray).

Nine hundred and one patients were recruited for sample $A$ and 215 for sample $B$. The range of age was 18 to 85 years, the mean age being 42 years. The ratio of paraplegics to tetraplegics was $58 \%: 42 \%$ and the ratio of men to women was $74 \%: 26 \%$. The sizes of all the characteristic values suggest that the patient sample investigated was highly representative for the Federal Republic of Germany. The sex distribution and also the proportions of paraplegics and quadriplegics correspond to the distributions given by Meinecke $^{9}$ for persons newly affected by SCI in Germany. All age groups above 18 years in the spinal 
cord injured population were definitely represented. Not only ill subjects were included, but also a substantial proportion $(59.4 \%)$ of subjects who were disabled but healthy and who only attended for routine examinations or repeat treatments.

\section{Results and discussion}

Since many different aspects were examined and literature was not available on all of them, the selected results and discussion have been summarized in several sections.

\section{Part I - Descriptive evaluation}

(a) Prevalence (of different types) of $P / D$ In the total patient population, sample A, we found $66 \%$ (591) of the patients experienced $\mathrm{P} / \mathrm{D}$ (this subgroup is referred to from now on as the pain group); $50 \%$ had pain alone, $11 \%$, painful dysaesthesia, and $5 \%$, distressing dysaesthesia with no pain. The remaining $34 \%$ (referred to from this point onward as the non-pain group) was made up of $10 \%$ of the total population who reported no $\mathrm{P} / \mathrm{D}$ at all and $24 \%$ who had non-

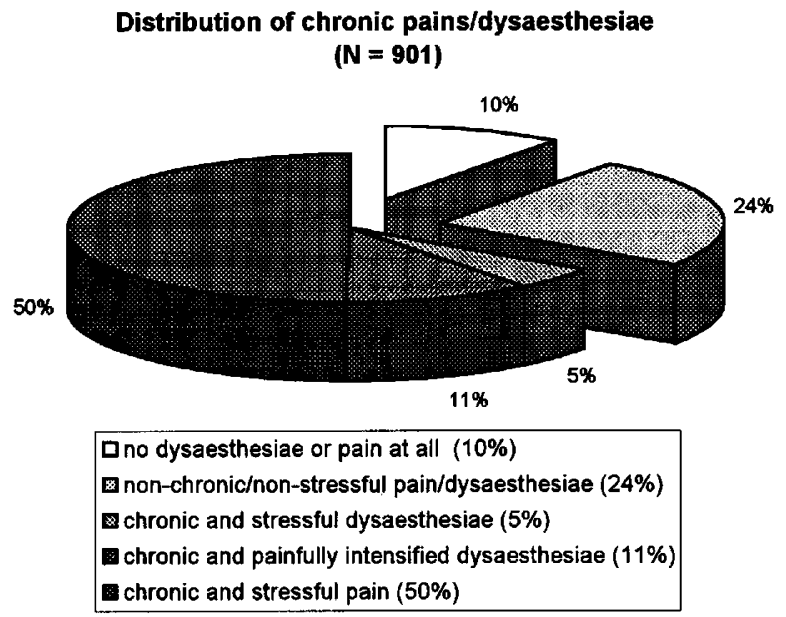

Figure 1

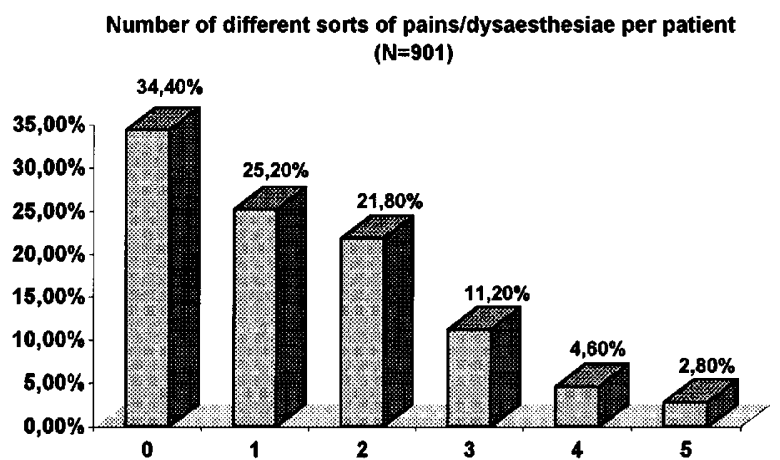

Figure 2 chronic $\mathrm{P} / \mathrm{D}$ or did not find their symptoms distressing (Figure 1). Besides the $34 \%$ of all patients with no $\mathrm{P} /$ $\mathrm{D}$, only one quarter of the patients in the total patient population had only one type of pain or only one dysaesthesia; all other patients - that is to say $41 \%$ were burdened with $\mathrm{P} / \mathrm{D}$ at several sites or of several types (Figure 2). As it was not possible to conduct a detailed interview on every $\mathrm{P} / \mathrm{D}$ present, the majority of pain patients were required to decide which of their symptoms they estimated as their main problem. Each patient was then questioned more closely on the subject of this main problem. The notes below describing the $\mathrm{P} / \mathrm{D}$ experienced thus refer exclusively to each patient's most distressing $\mathrm{P} / \mathrm{D}$ (so do the percentages above). Percentages given for the pain group are generally based on 591 patients as $100 \%$.

(b) Onset and change over time of chronic $P / D$ The onset of $\mathrm{P} / \mathrm{D}$ was generally soon after $\mathrm{SCI}$ : within the

\section{Onset of chronic pain in relation to onset of paraplegia} ( $N=591)$

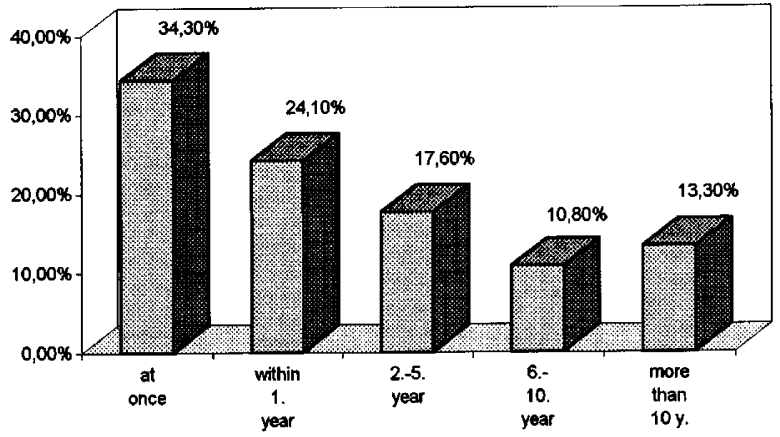

Figure 3
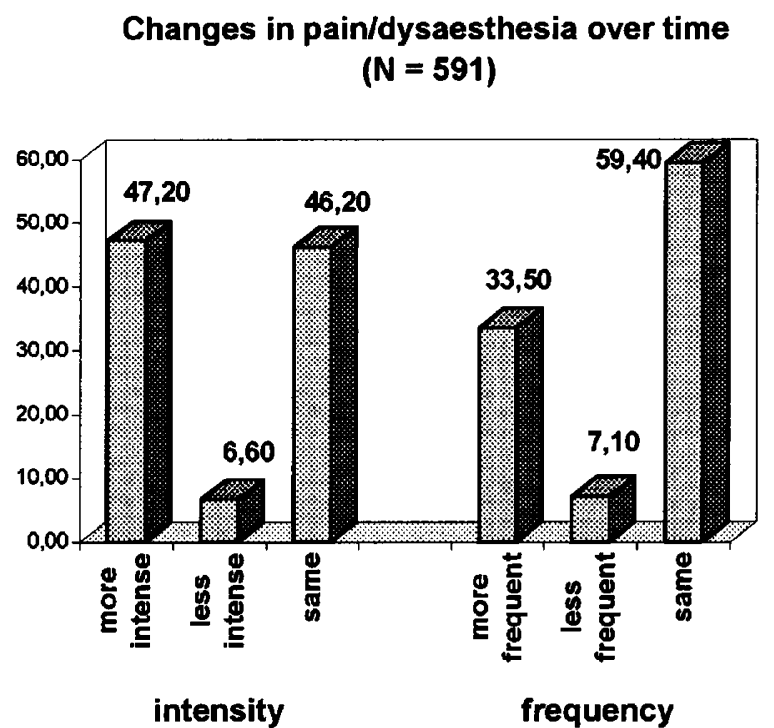

Figure 4 
first year in $58 \%$ of cases. In $34 \%$ of cases the patients even declared that $\mathrm{P} / \mathrm{D}$ had begun 'immediately' when they sustained SCI. With persisting duration of paralysis, the new onset of chronic $\mathrm{P} / \mathrm{D}$ declines. Nevertheless, in $13 \%$ of patients in the pain group $\mathrm{P} /$ $\mathrm{D}$ had not started until more than 10 years after they were paralysed (Figure 3). The intensity of $\mathrm{P} / \mathrm{D}$ grew less over time in only $7 \%$ of the pain patients; the same is true of the frequency of pain. The opposite, increasing intensity of pain, was experienced by $47 \%$ of patients in this group, and more frequent pain, by $34 \%$. In the remaining cases, the intensity and frequency of pain remained unchanged (Figure 4).

(c) Intensity of actual $P / D$ and general tolerability value of $P / D$ Assessment of the intensity of $\mathrm{P} / \mathrm{D}$ on a $10 \mathrm{~cm}$ long visual analogue scale (VAS) yielded a distribution that was clearly right-skewed. Pain intensities of five or less were found in only $30 \%$ of the patients, while the remaining $70 \%$ of the pain-group reported intensities of six and more for their pain or dysaesthesia (Figure 5) and 43\% had VAS values over seven. A tolerability value for $\mathrm{P} / \mathrm{D}$ in general was determined on the visual analogue scale for each patient on the basis of the question: "What intensity of pain could you quite well live with?' In this case a relatively symmetrical distribution emerged. Fifty six percent of the patients interviewed believed they would be well able to cope with $\mathrm{P} / \mathrm{D}$ with an intensity of five or less, while the remaining $44 \%$ thought they could cope with an intensity of six or higher, $30 \%$ of those interviewed thought they would be able to live tolerably well even with intensities of seven and more (Figure 6).

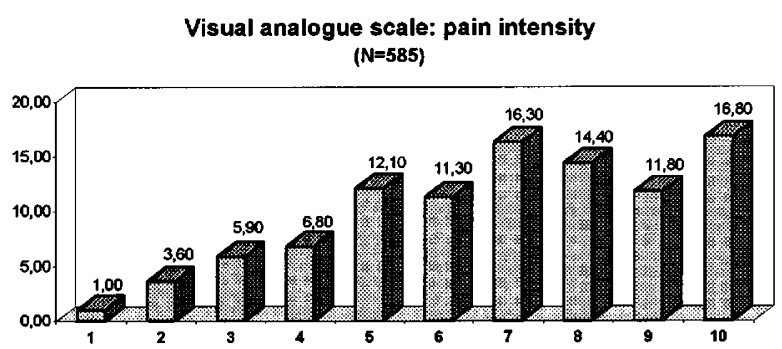

Figure 5

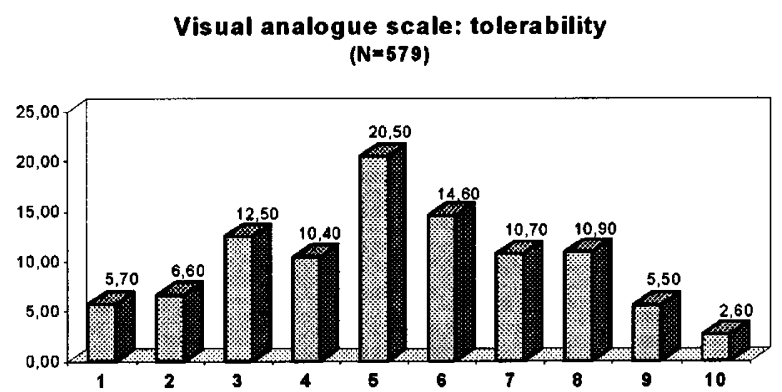

Figure 6 (d) Subjective distress resulting from $P / D$ and restrictions in daily life The patients in the pain group each assessed the distress resulting from their main $\mathrm{P} / \mathrm{D}$ on a 4-point scale (Figure 7). For this variable, as for the intensity of $\mathrm{P} / \mathrm{D}$, we found a right-skewed distribution. The highest percentage of patients, namely $77 \%$, fell in the subgroup who felt they were rather or very badly distressed as a result of their $\mathrm{P} / \mathrm{D}$. Only a small proportion, $6 \%$, experienced the main problem as hardly burdensome at all. When asked about any restrictions in daily life as a result of $\mathrm{P} / \mathrm{D}, 23 \%$ of the patients said their symptoms had not had any effect on their daily life. In contrast to these, $23 \%$ reported that their daily routine was markedly or almost completely limited by pain (Figure 8). It is noteworthy in this context that some patients commented during the interview that they certainly had severe pain but were not willing to let the pain restrict their activities. These patients followed their planned or accustomed routine despite pain and they explain some of the astonishing cases in which severe pain is not correlated with a restricted daily routine.

(e) Localization The localization of $\mathrm{P} / \mathrm{D}$ in relation to the level of the lesion can be seen from the Table below (Figure 9). For $86 \%$ of the $\mathrm{P} / \mathrm{D}$ the patients specified sites that were exclusively below the lesion

Degree of subjective stress resulting from the main pain/dysaesthesia $(N=591)$

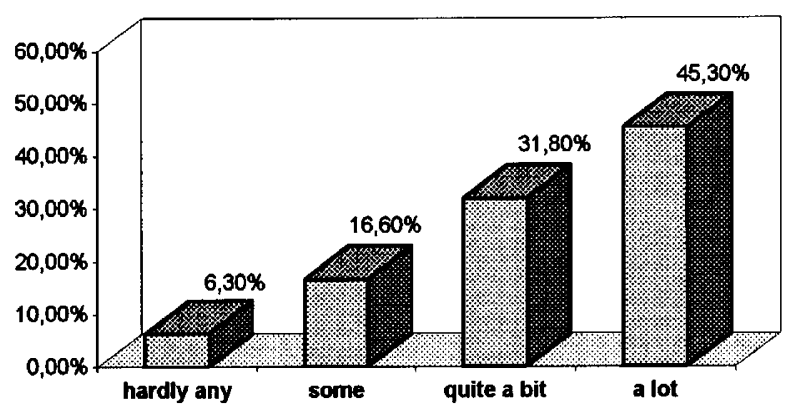

Figure 7

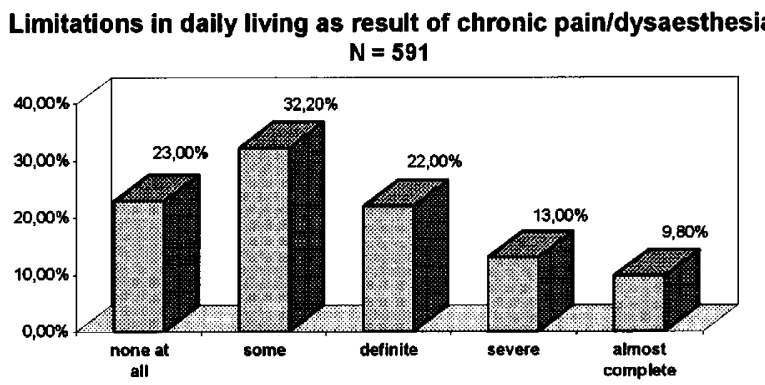

Figure 8 
and/or in the transition zone. A further $8 \%$ of $\mathrm{P} / \mathrm{D}$ (rows 4 and 5 in the Table) extended at least into the transition zone or even into the infralesional region. Only $6 \%$ of pains, namely the exclusively supralesional pains, were localized in the non-paralysed part of the body.

(f) Classification in the medical pain diagnosis The following pain classification (painless dysaesthesiae were not assessed) was elaborated on the basis of the literature as a working hypothesis: "pain linked with spasm', 'visceral pain', 'muscle pain', 'skeletal pain', 'deafferentation pain' and 'other' - deafferentation pain means the burning infralesional pain or so-called phantom pain characteristic of SCI patients the causation of which is attributed by the physicians to the lesion of the spinal cord, medullary cone or the cauda equina. Among 462 patients for whom a medical pain diagnosis was recorded (multiple diagnoses were permitted) pain was most frequently, in $44 \%$ of cases, classified as deafferentation pain, followed by skeletal pain with $27 \%$ and muscle pain with $24 \%$, the last two categories occurring together in about two-thirds of the patients affected. Only $6 \%$ of the patients had visceral pain and $9 \%$, pain linked with spasm.

(g) Quality of $P / D$ - descriptions of $P / D$ When they were interviewed patients were asked to describe their $\mathrm{P} / \mathrm{D}$ in their own words. Multiple descriptive terms were allowed. Most of the descriptions given could be grouped, according to a rating by five examiners, into the following categories (Figure 10): burning, tingling, stabbing, tight/tense feeling, hardening, cramping, pulling/tearing. Those that did not fit into any of these categories were classed together under 'other'. According to this summary, the categories of burning, tingling and stabbing pain were fairly equally represented, each occurring in $23 \%$ to $24 \%$ of patients, closely followed by tight/tense feelings, which were reported by $21 \%$. The types of pain that could not be classified in the above-mentioned groups (category 'other') account for a considerable proportion of $23 \%$.

Part II-Discussion of descriptive evaluation

Frequency and intensity We believe we have ascertained quite precise and representative data on the prevalence of chronic $\mathrm{P} / \mathrm{D}$ of varying intensities in SCI. It can therefore be assumed that $66 \%$ of SCI patients are burdened with chronic $\mathrm{P} / \mathrm{D}$. If only the painful symptoms were considered, the corresponding percentage would still not be substantially lower: in the total patient population $61 \%$, and below the level of lesion in $54 \%$. Since the frequencies of pain in SCI patients reported in the literature are often linked to the reported intensity, discussion on this point is fairly difficult. Botterell et $a l^{10}$ gave a substantially higher percentage of pain patients $(94 \%)$ in their total population than we found in our study. Both of the
Localization of the chronic pains and dysaesthesiae $(\mathrm{N}=591)$

$\begin{array}{lc}\text { Localization of main pain/dysaesthesia } & \begin{array}{c}\text { Proportion of the pains / } \\ \text { dysaesthesiae }\end{array} \\ \text { Below lesion } & 47 \% \\ \text { Below lesion and in transition zone } & 22 \% \\ \text { Transition zone } & 17 \% \\ \text { Above lesion and in transition zone } & 5 \% \\ \begin{array}{l}\text { Below and above lesion and in } \\ \text { transition zone }\end{array} & 3 \% \\ \text { Above lesion } & 6 \%\end{array}$

Figure 9

Types of pain ( $n=591$ patients, multiple entries allowed)

$\begin{array}{lcc}\text { Type of pain } & \text { No. of entries } & \begin{array}{c}\text { Percentage of all pain patients } \\ \text { Burning }\end{array} \\ \text { Tingling } & 144 & 24,4 \% \\ \text { Stabbing } & 136 & 23,0 \% \\ \text { Tight, tense feeling } & 136 & 23,0 \% \\ \text { Hardening, cramping } & 124 & 21,0 \% \\ \text { Pulling, tearing } & 79 & 13,4 \% \\ \text { Other } & 87 & 14,7 \% \\ & 137 & 23,2 \%\end{array}$

Figure 10

studies included patients with quite mild pain. It is possible, however, that in Botterell's group acute or not distressing pains were also included. Our results on the frequency of pain are more in keeping with those of Nepomuceno et al, ${ }^{11}$ who registered $48 \%$ of pain patients and Woolsey ${ }^{4}$ who found that $49 \%$ of patients had slight to moderate pain and $18 \%$ had severe pain. Paeslack $^{12}$ reported that $51 \%$ of his sample were pain patients. Rose et $a l^{13}$ conducted a postal survey among all the (1091) members of the Spinal Injuries Association, a self-help group for SCI patients in Britain; the 885 evaluable questionnaires returned showed that $69 \%$ of these patients suffered from pain. Though one might challenge the comparability of a clinical study to a postal survey we think our study is comparable to theirs quite well because both of the studies strived to register a total population, covered a high percentage of available patients and therefore can claim representativeness. The data in the literature on the frequency of intense pains - if we once accept the following terms describing degrees of intensity as synonymous - are less divergent: $27 \%$ of patients in a survey with severe pain or pain necessitating therapy according to Davis and Martin, ${ }^{14}$ and $30 \%$ with debilitating pain according to Botterell et al. ${ }^{10} \mathrm{We}$ found that values of more than seven on VAS, which are generally regarded as reflecting severe pain, were given for $43 \%$ of the $\mathrm{P} / \mathrm{D}$ 
reported; referred to the total patient population this means that $28 \%$ of all our study patients were subject to severe pain. According to this, with an overall review of the literature and of our results a proportion of $20 \%$ to $30 \%$ of SCI patients experiencing severe pain can be regarded as realistic. Even less equivocal are the data on extremely severe pain: Botterell et al ${ }^{10}$ described the pain as bad enough to make an operation necessary in $7 \%$ of cases, while Munroe ${ }^{15}$ estimated pain as 'disabling' in $6 \%$. In a separate question about attempts at pain therapy, $8 \%$ of our pain patients (ie $5.3 \%$ of the total sample) also reported that they had tried an operation for treatment of their pain. Thus, in $5 \%$ to $7 \%$ of cases pain has to be estimated as extremely severe, leading to extreme treatment trials. On the other hand, in some of our study cases the pain experienced presumably caused so little distress or the hope of effective therapy was so remote that the patients had not consulted a doctor about it $(14.6 \%$ of the pain group) and/or no therapy had been tried $(22.84 \%$ of the pain group).

Onset and changes over time As a rule, the onset of pain is early after sustained SCI, but the possibility of a new onset of $P / D$ cannot be excluded even after a very long duration of paralysis. The prospects of improvement - in our study $7 \%$ for intensity and frequency - are far from good, as confirmed by Rose et $a l^{13}$ The probability of no change or of worsening is substantially higher, with worsening of the severity of pain even more likely than an increased frequency. In our search for improvements in pain we used a separate question to ascertain all the patients who had formerly experienced $\mathrm{P} / \mathrm{D}$ but in whom these symptoms had completely disappeared, either spontaneously or as a result of treatment. They accounted for $5.8 \%$ of the total study population and had been allocated to the non-pain group.

Tolerability, distress and restrictions resulting from $P /$ $D$ A very high percentage $(75 \%)$ of the pain group felt their symptoms caused them some or severe distress. This is clearly a larger proportion than the one defined above as suffering from severe pain $(43 \%$ with a score of over seven on the VAS). This suggests that $\mathrm{P} / \mathrm{D}$ of fairly mild and moderate intensity are also experienced as very distressing. We had rather expected that the tolerability value would give a left-skewed curve, with a peak approximately in the lower third as it was found by Seemann and Lang $(1992 \text {, p. } 55)^{8}$ for cancer patients. To our astonishment, however, markedly higher pain intensities were still designated as tolerable. Maybe SCI patients accept higher levels of pain because they know that contrary to cancer patients higher pain levels do not signify a life threatening change in their bodies. As a measure of the tolerability of the $\mathrm{P} / \mathrm{D}$ currently being experienced, for each patient we calculated the quotient of the pain intensity of his/her main symptom and the general tolerability value he/she had given. In $35 \%$ of the patients the intensity was lower than the tolerability value (quotient $<1$ ), which we interpreted as meaning the actual $\mathrm{P} / \mathrm{D}$ was tolerable. In $36 \%$ the intensity was somewhat higher $(1 \leqslant$ quotient $\leqslant 2)$, and in $29 \%$ substantially higher (quotient $>2$ ), than the value given for tolerability (Figure 11). Comparison with the distribution of the subjective distress, however, shows that at least $10 \%$ of the pains that we thought were tolerable were regarded by the patients as rather or very distressing. The proportion of patients who were not restricted in their daily routine as a result of $P / D$ $(23 \%)$, is about the same as the proportion who experienced their symptoms as distressing them hardly at all or only somewhat $(23 \%)$. We found a close correlation between the two variables 'subjective distress' and 'restriction in daily routine' $(P=0.001$, Wilcoxon test) and also between the variables 'restriction in daily routine' and 'intensity of $\mathrm{P} / \mathrm{D}$ ' and between 'intensity of $\mathrm{P} / \mathrm{D}$ ' and 'subjective distress' $(P=0.0001$, Wilcoxon test, in each case). Some degree of overlap in the meaning of these variables must therefore be assumed.

On the basis of the responses to a questionnaire on pain that appeared in the 'Paraplegiker' (magazine issued by the Deutsche Fördergemeinschaft der Querschnittgelähmten e.V. (German support association for SCI patients)), Gerner ${ }^{16}$ reported on 100 patients with pains: multiple entries in the following categories were allowed, and $19 \%$ of the patients described their pains as most distressing, $18 \%$, as just bearable, $10 \%$, as intolerable. Twenty-four percent reported restrictions in their life with other people and $22 \%$, restrictions in other activities; these values correspond to the proportion of patients in our study $(23 \%)$ which were severely to almost completely restricted in their daily life by $\mathrm{P} / \mathrm{D}$.

Localization By far the most P/D (86\% to $94 \%$ ) were experienced - at least partly - in the paralysed body area. From the patients' viewpoint most of the $\mathrm{P} / \mathrm{D}$ consequently might be attributed to their paralysis. Therefore SCI patients with $\mathrm{P} / \mathrm{D}$ may develop a more

\section{VAS: pain intensity in relation to tolerability} $(\mathrm{N}=563)$

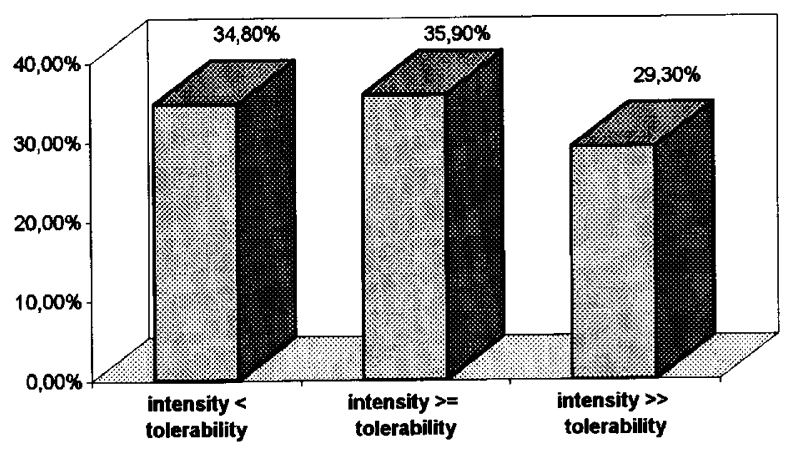

Figure 11 
negative attitude to paralysis as such than would be the case if pain were not present - regardless of whether a doctor would see things the same way. Presumably this is not so, however, since only in $44 \%$ of cases the pain was regarded as deafferentation pain by the physcians. From the literature (see above) we had expected a higher proportion.

Quality of pain and medical pain diagnosis The assignment of the individual descriptive qualities to the medical pain diagnoses was much less unequivocal than we had expected from the literature. Discrepancies also emerged in the case of deafferentation pain in which we took special interest. In the literature, this sort of pain is fairly consistently described as 'burning' (eg Aalam, ${ }^{17}$ Burke and Woodward). ${ }^{18}$ Other authors mention the burning quality in addition to further qualities (eg Davidoff et $a l,{ }^{19}$ Frisbie and Aguilera). ${ }^{20}$ In the free descriptions given by the patients, however, the frequent specification of burning pain was not confirmed. Only $25 \%$ of all main pains were described as burning in nature, as against $44 \%$ that were judged to be deafferentation pains, which means that approximately half of the deafferentation pains were described as having a different quality than 'burning'. It was observed in addition that 'burning' also was used as a description of skeletal pain by the patients. This means that the pain quality alone, when described in the patient's own words, without the consideration of further characteristics, such as its localization, is not on any account enough to permit a pain diagnosis or a classification.

Part III - Relationships between P/D and other variables (a) Relationships between $P / D$ and demographic and medical data. Gender There was a tendency with women suffering from $\mathrm{P} / \mathrm{D}$ more often than men, but the difference did not prove significant (Chi Square test, $P=0.066)$.

Age at the time of study, age at onset of paraplegial tetraplegia With reference to age at the time of the study (divided into groups) it appeared that patients in the higher age groups were more likely to have been allocated to the pain group than were patients in the younger age groups; this relationship was highly significant (Chi-square test, $P=0.001)$. We found a very significant correlation (Chi-square test, $P=0.002$ ) between age at SCI (divided into 10-year groups) and belonging to the pain group. Persons who sustained SCI at the age of 18 or younger were less at risk of suffering from chronic $\mathrm{P} / \mathrm{D}$, persons older than 38 at the time of injury were more at risk of $\mathrm{P} / \mathrm{D}$, especially the group aged $48-57$ years.

Disturbances of sweat secretion When the patients with hyperhidrosis were compared with those in whom no disturbance of sweat secretion or only anhidrosis was present, we found pain was significantly more frequent in the patients with hyperhidrosis than in those without
(Chi-square test, $P=0.018$ ). When on the other hand the analogue procedure was made for anhidrosis there was no demonstrable correlation with pain.

Paraosteoarthropathia (POA) All the patients in sample B were asked whether or not to their knowledge they had paraosteoarthropathia. In addition, all existing X-rays were examined. For statistical evaluation, all patients with a documented POA (by questioning or X-ray) were classed in one group (regardless of POA localization). A statistically significant correlation between POA and belonging to the pain group could not be proven. There was one striking feature of the distribution, however: with existing POA the probability of belonging to the pain group was elevated; nonetheless, for patients without POA the likelihood of pain was not lowered (Chi Square test, $P=0.12$ ).

Type of paralysis (central, mixed, peripheral lesion) When the types of paralysis were allocated to the categories 'central lesion' (ie level of T11 or above), 'mixed lesion' (ie level of T12 or L1 and some signs of spasticity in muscles or bladder) and 'peripheral lesion' (ie level of L1 or lower and no signs of spasticity at all in muscles or bladder), the group with peripheral paralysis had an elevated probability of pain, in the group with mixed paralysis the frequency of pain was a little elevated, but the probability of pain was not lowered for the group with central paralysis. This relationship also was not statistically significant (Chi Square test, $P=0.07$ ).

Problems with rectal paralysis and psychosomatic disturbances of wellbeing In our study, a positive correlation (Chi-square test, $P=0.017$ ) appeared between problems with the rectal paralysis (recorded when the history was taken) and belonging to the pain group. But, the risk of pain is increased only if there are problems with incontinence and with bowel evacuation concurrently; if only one of these problems is present the probability of pain is not increased. Part of the interview was devoted to the 'Beschwerdenliste' (list of (psychosomatic) complaints) by von Zerssen, ${ }^{21}$ which includes a wide variety of psychosomatic disturbances of wellbeing, ranging from sleep disturbances through palpitations to restless legs. For each of the disturbances patients were asked to decide whether or not they suffered from it and to what extent. The sum of scores of this list was highly significantly elevated in pain patients as compared to the non-pain group (Kruskal-Wallis - Test of rank sums, $P=0.0001)$.

No relationship to the presence of $P / D$ emerged for the following variables:

- traumatic/non-traumatic causation of SCI

- complete/incomplete paraplegia/tetraplegia

- (in case of traumatic SCI:) spinal operation/no spinal operation as a component of the initial treatment 
- duration of paraplegia/tetraplegia

- problems with the treatment of bladder paralysis (medical assessment)

- frequency of urinary tract infections (patients' assessment)

- existing heart disease (all sorts)

- (in case of traumatic SCI:) severity of concomitant injuries.

(b) Correlations between $P / D$ and psychosocial variables. Attribution of causation Contrary to our expectations, there was no correlation between $\mathrm{P} / \mathrm{D}$ and the cause to which SCI was attributed. Patients who regarded their paralysis as caused by other persons or external hazardous events did not suffer pain more frequently than those who considered their condition self-caused.

Aspects of coping with paraplegia/tetraplegia Information on coping with the disability resulting from SCI was ascertained by means of various questions and comprises three aspects, which are represented by the following questions of the questionnaires:

- How did you picture your life as a paraplegic/ tetraplegic when you were discharged from your initial rehabilitation?

- How well do you cope overall with the fact of being a paraplegic/tetraplegic?

- In general, to what extent do you feel paraplegia/ tetraplegia is a burden?

As can be seen from Figure 12, the patients who imagined life with paraplegia/tetraplegia as simpler than it turned out to be afterwards and who were later confronted with unexpected problems had a significantly higher probability of chronic $\mathrm{P} / \mathrm{D}(P=0.035)$. Those who estimated that they coped well with the fact of their paralysis had a lower probability of chronic P/D (Figure 13). Those who thought that they coped only moderately well or not at all well had a significantly higher likelihood of chronic $\mathrm{P} / \mathrm{D}$ $(P=0.001)$. The more paralysis was experienced as a
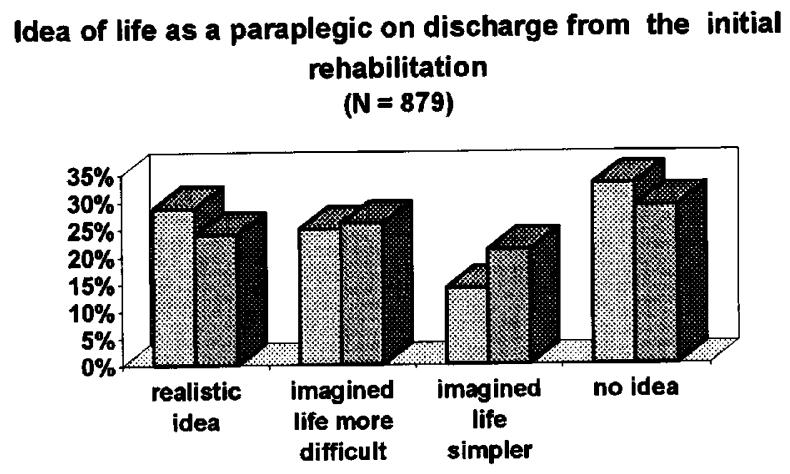

⿴囗大 kein chron. Schmerz chron. Schmerz

Figure 12 burden (5-point scale), the higher was the likelihood of chronic $\mathrm{P} / \mathrm{D}(P=0.001)$. This correlation also was highly significant (Figure 14).

Depression Depressed mood was ascertained with the aid of the 'Paranoid-Depressivitätsskala' (paranoiddepression scale) of von Zerssen ${ }^{22}$ the values of which are intended to be indicative of depressive mood and not of clinical depression. There was a highly significant positive correlation between chronic $\mathrm{P} / \mathrm{D}$ and depressed mood $(P=0.0001, r=0.26)$.

Experiences of loss The subjective experience of loss sustained through SCI is exemplified here by the following selected questions of the questionnaires:

- How did you feel were the changes in working life as a result of SCI (including future career plans)?

- Did your social life change as consequence of SCI and if so, how do you assess these changes?

- Did you have to move because of SCI and if so, was it difficult to make this move and have you lost friends and acquaintances because of moving?

We found a negative view of changes in working life (and also changes to future career plans) very

\section{Overall coping with the fact of being a paraplegic $(\mathrm{N}=900)$}

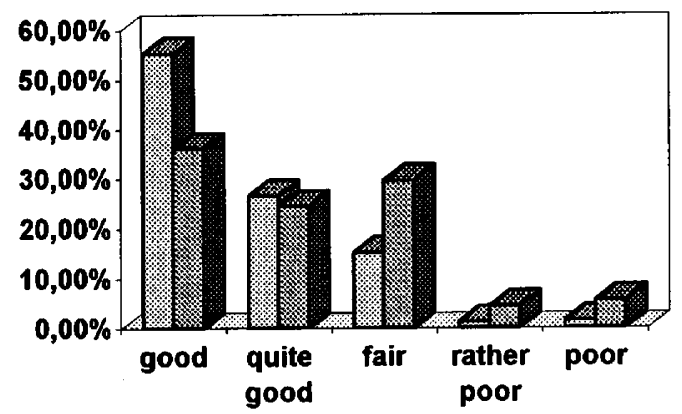

no chronic pain/dysaesth. 0 chronic pain/dysaesth.

Figure 13

Extent to which paraplegia is experienced as a burden $(\mathbf{N}=\mathbf{8 7 7})$

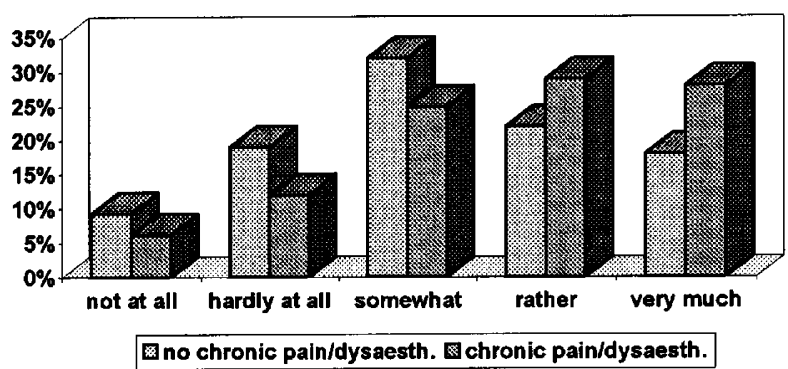

Figure 14 
significantly more frequently $(P=0.004)$ in patients with chronic $\mathrm{P} / \mathrm{D}$ (Figure 15). Positive, neutral or ambivalent views were reported more by patients of the non-pain group. Patients with chronic $\mathrm{P} / \mathrm{D}$ tended to experience changes in the social sector as negative or ambivalent. Positive changes or none at all in the social area were found more often in the patients without $\mathrm{P} / \mathrm{D}(P=0.265-$ not significant $)$.

Accommodation: Among the 214 patients (sample B) who were interviewed to this aspect

- $47 \%$ had had to move to different accommodation after becoming paralysed,

- $20 \%$ reported that they had found it difficult to make this move,

- $19 \%$ had experienced loss of friends and acquaintances because of moving.

Pain patients were found with an elevated frequency only in the group of patients for whom a house move was necessary and also involved the loss of social relationships (third group, above) - in this point statistical testing could not be carried out because of small numbers.

Life satisfaction Life satisfaction in different aspects of life as well as in general was elicited by a slightly modified version of the questionnaire 'Fragen zur Lebenszufriedenheit' (Questions concerning life satis-

\section{Subjective assessment of changes in working life $(\mathbf{N}=\mathbf{7 7 2})$}

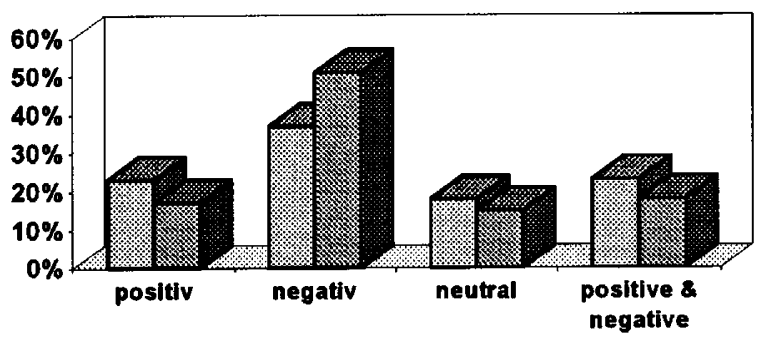

no chron. pain/dysaesth. 8 chron. pain/dysaesth.

$>$ Figure 15

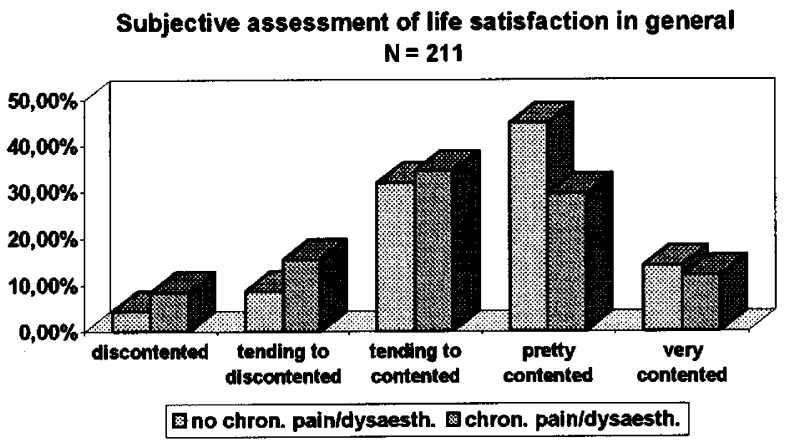

Figure 16 faction) by Herschbach and Henrich. ${ }^{23}$ As result of the general assessment Figure 16 shows a clear tendency (which does not, however, reach statistical significance): pain patients tend to be dissatisfied with their life in general, while patients of the non-pain group were more likely to report that they are fairly or very contented overall $(P=0.078)$.

\section{Part IV-Discussion on relationships}

Demographic and medical data Levi et al ${ }^{24}$ also report less severe problems with pain for the patients in their study population who sustained spinal cord injury while they were still young. Also in accordance with our findings Wagner Anke et $a l^{25}$ found a significant correlation between older age at questioning and pain in their sample. Whether or not this is a consequence of greater plasticity of the central nervous system in youth decreasing with age, remains speculation. The correlation of age at the time of the interview with belonging to the pain group might also reflect an age-specific phenomenon rather than a paraplegia-specific one. Older people in the nondisabled population also have an elevated risk of suffering from chronic painful conditions. At the same time, it must be borne in mind that those who became paralysed when they were older were also in the older age groups when they were interviewed. On the other hand, longer duration of paralysis was not coupled with higher frequencies of pain.

Astonishingly, but definitely, the collected data revealed no indication of any statistical correlation between pain and various characteristics of the spinal lesion, p.e. traumatic/non-traumatic, complete/incomplete lesion, operated/non-operated spinal trauma, concomitant injuries/no concomitant injuries, level of lesion in terms of paraplegia and tetraplegia. In their sample of 46 patients, whom they followed up within 2 years after SCI Wagner Anke et $a l^{25}$ also, could not prove a correlation between pain and gender, pain and SCI level and pain and Frankel classification (grouped in complete (grade A) and incomplete (grade B-E) lesions).

Statistically significant relationships between pain and medical data could only be proven in the case of certain problems with bowel evacuation, certain disturbances of sweat secretion and psychosomatic complaints - all of which can be seen in relation to the vegetative nervous system. In the case of the psychosomatic symptom list, in view of the general vegetative changes caused by the paralysis we had not expected such a close and unequivocal correlation as examination of the data ultimately revealed.

Psychosocial variables A highly significant correlation $(P \leqslant 0.0001)$ between belonging to the pain group and high scores on the depression had been expected. The correlation of depressive mood states with pain is known from reports on other groups affected by chronic pain, but it was also confirmed very clearly in our study group. 
All in all, it has become clear that coping with disability and subjective assessment of losses correlate very closely with pain. With regard to changes in working life, it must be re-emphasized at this point that changes themselves were not the decisive factor. The fact of having to change jobs or retrain was relatively insignificant compared with the subjective assessment of this change. The situation is similar, as described above, with moving to different accommodation.

The relationship between degree of contentment with life and chronic pain (provable as a tendency only) was not as close as we expected. A possible explanation for this might be the fact that a large proportion of the patients regardless of pain are capable to feel content in other sectors of their life and - as in the case of the daily routine - are not prepared to let pain take over and deprive them of this contentment.

For all the correlations we found between pain and other variables it must be emphasized that the causative direction of the relationship remains unclear however significant the correlation might be.

\section{Conclusions}

In view of the characteristics of our patient population the experience of chronic $\mathrm{P} / \mathrm{D}$ must be regarded as a frequent accompanying symptom in SCI patients, with a prevalence of $66 \%$. If reports of dysaesthesia alone are excluded, the prevalence remaining for pains and painful dysaesthesiae is still $61 \%$.

The experience of $\mathrm{P} / \mathrm{D}$ is highly distressing in the majority of cases and restricts the patients in their daily routine.

As compared with medical variables, statistically more significant correlations were found between pain and psychosocial variables - particularly depressive mood, psychosomatic symptoms and coping with paralysis - longitudinal studies should be performed to follow up the development of these correlations over time for about $2-3$ years from the onset of paralysis. In this way it might be possible to determine the causal direction of these correlations, which we were not able to do because our study was a crosssectional one.

Because of the large number of persons affected, it is important to continue research directed at effective forms of therapy. In particular, studies should be performed to check whether an early start of therapy before pain becomes chronic will have better results. The efficacy of early psychological help and therapeutic approaches, for example directed at coping with SCI and any pain that may occur, should be subjected to trials with scientific back-up.

\section{References}

1 Pollock LJ et al. Pain below the level of injury of the spinal cord; A.M.A. Arch Neurol Psychiat 1951; 65: 319-322.
2 Wright LR, Sweet WH. Intractable pain in traumatic paraplegia; 17 th Spinal Cord Injury Conference 29/30 Sept. 1 Oct. 1969; $76-$ 89.

3 Melzack R, Loeser JD. Phantom body pain in paraplegics: Evidence for a central 'pattern generating mechanism' for pain. Pain 1978; 4: 195-210.

4 Woolsey RM. Chronic pain following spinal cord injury. Journ Am Paraplegia Soc, New York, 1986; 9: 39-41.

5 Donovan WH, Dimitrijevic MR, Dahm L, Dimitrijevic M. Neurophysiological approaches to chronic pain following spinal cord injury. Paraplegia 1982; 20: $135-146$.

6 Maury M. A propos du traitement de la douleur chez les paraplégiques. Annales de Médecine Physique, 20/4. Paris 1977; $376-381$.

7 Waisbrod H, Hansen D, Gerbershagen HU. Chronic pain in paraplegics. Neurosurgery 1984; 15: $933-934$.

8 Seemann H, Lang H. Erleben und Bewältigung von Schmerz bei Krebserkrankungen; Forschungsbericht des gleichnamigen Projektes des Projektträgers GSF - Forschungszentrum für Umwelt und Gesundheit; GSF München 1992, 55 and appendix.

9 Meinecke F-W. BG-Anlaufstelle für die Vermittlung von Betten für Querschnittgelähmte - Erfahrungsaustausch über 5 Jahre. Die Berufsgenossenschaft 1, 1983, 40-46.

10 Botterell EH, Callaghan JC, Jousse AT. Pain in paraplegia, Clinical management and surgical treatment. Proc Roy Soc Med, Vol. 47, September 1953, Toronto, 281-288.

11 Nepomuceno C et al. Pain in patients with spinal cord injury. Arch phys Med Rehab, Vol. 60/12, Chicago, 1979, 605-609.

12 Paeslack V. Schmerzempfindung and Phantomerlebnisse in: Paeslack V: Internistische Störungen beim Paraplegiker; Thieme, Stuttgart, 1965, 85-90.

13 Rose M, Robinson JE, Ells P, Cole JD. Pain following spinal cord injury: results from a postal survey. Pain 1988; 34: $101-$ 102.

14 Davis L, Martin J. Studies upon spinal cord injuries, the nature and treatment of pain. Journ Neurosurg 1947; 4: 483491.

15 Munroe D. Two year end results of rehabilitation of veterans with spinal cord and cauda equina injuries. J Amer med Ass 1942 (150), 1-16 quoted in: Melzack R, Loeser JD: Phantom body pain in paraplegics: Evidence for a central 'pattern generating mechanism' for pain. Pain 1978; 4: 195-210.

16 Gerner HJ. Die Querschnittlähmung - Erstversorgung, Behandlungsstrategie, Rehabilitation; Blackwell Wissenschaft, Berlin 1992, $128-130$

17 Aalam M. Der Schmerz nach traumatischen Rückenmarksschäden aus Thom H. Diagnose und Therapie des Schmerzes; Uelzen, $1980,161 \mathrm{f}$.

18 Burke DC, Woodward JM. Pain and phantom sensation in spinal paralysis. In: Vinken PJ, Bruyn GW (eds). Handbood of clinical neurology, Vol. 26, North Holland Publishing Co, Amsterdam 1976, 489-499.

19 Davidoff $\mathrm{G}$ et al. Function-limiting dysesthetic pain syndrome among traumatic spinal cord injury patients: a cross-sectional study. Pain 1987; 29: $39-48$.

20 Frisbie JH, Aguilera EJ. Chronic pain after spinal cord injury: an expedient diagnostic approach. Paraplegia 1990; 28: $460-$ 465.

21 v. Zerssen D. Die Beschwerdenliste; Beltz-Verlag, Weinheim, 1976.

22 v. Zerssen D. Paranoid-Depressivitätsskala; Beltz-Verlag, Weinheim, 1976

23 Herschbach P, Henrich G. Der Fragebogen als methodischer Zugang zur Erfassung von 'Lebensqualität' in der Onkologie. In: Schwarz R et al. (Hrsg.) Lebensqualität in der Onkologie; Zuckschwerdt-Verlag, München, Bern, Wien, 1991, 34-46.

24 Levi R, Hultlin C, Seiger $\AA$. The Stockholm Spinal Cord Injury Study: 2. Associations between clinical patient characteristics and post-acute medical problems. Paraplegia 1995; 33: $585-594$.

25 Wagner Anke AG, Stenehjem AE, Kvalvik Stanghelle J. Pain and life quality within 2 years of spinal cord injury. Paraplegia 1995 ; 33: $555-559$ 